\section{Cureus}

\title{
A Case of Purple Urine Bag Syndrome in a Spastic Partial Quadriplegic Male
}

\author{
Sibghat Tul Llah ${ }^{1}$, Salman Khan ${ }^{1}$, Atman A. Dave ${ }^{2}$, Amelia Jane A. Morrison ${ }^{2}$, Swapna Jain ${ }^{2}$ \\ , David Hermanns ${ }^{3}$ \\ 1. Department of Internal Medicine, University of Missouri Kansas City (UMKC) 2. Medical Education, \\ Saint Luke's Hospital of Kansas City 3. Department of Medicine, University of Missouri Kansas City \\ (UMKC)
}

$\square$ Corresponding author: Sibghat Tul Llah, sibghattulllahn@umkc.edu Disclosures can be found in Additional Information at the end of the article

\section{Abstract}

Purple bag urine syndrome (PUBS) is a benign and unique phenomenon of the urine turning a deep violet color within the urinary catheter tubing and bag. This phenomenon is commonly encountered in patients indicated with long-term catheter placement or, in certain conditions like chronic constipation, alkaline urine, limited ambulation, and, in terms of gender distribution, the female sex, predominates. PUBS gets its name from a unique phenomenon that takes places inside the gut where tryptophan (an amino acid) is metabolized, producing blue and red hues which together emanate a deep violet color. Here, the case of a middle-aged male patient with a suprapubic catheter in situ, following trauma causing spastic partial quadriplegia, is being presented with PUBS due to UTI secondary to Proteus vulgaris. The risk factors, in this case, include chronic constipation and recurrent urinary tract infections (UTIs).

Categories: Internal Medicine, Infectious Disease, Nephrology

Keywords: purple urine, purple urine bag syndrome

\section{Introduction}

Purple urine bag syndrome (PUBS) is a rare clinical entity and was first reported in 1978. It is characterized by a purplish discoloration of the urine in patients with urinary tract infections due to specific organisms and generally affects chronically debilitated patients requiring longterm indwelling urinary catheters. The mechanism entails recurrent urinary tract infections with bacteria containing sulphatase and phosphatase enzymes, which result in the formation of pigments indirubin (red) and indigo (blue). These pigments consequently turn the urine purple.

Received 12/13/2015 Review began 12/21/2015 Review ended 03/29/2016 Published 04/01/2016

\section{C) Copyright 2016}

Tul Llah et al. This is an open access article distributed under the terms of the Creative Commons Attribution License CC-BY 3.0., which permits unrestricted use, distribution, and reproduction in any medium, provided the original author and source are credited.

\section{Case Presentation}

A 52-year-old African-American male presented to the emergency department with a one-week history of dark urine and abdominal pain. His past medical history was significant for spastic partial quadriplegia (C5-C7, incomplete) secondary to trauma six years prior, neurogenic bladder with suprapubic catheter placement five years prior, recurrent urinary tract infections (UTI), depression, and chronic constipation. He complained of pain and could localize it in the right lower quadrant of the abdomen with no radiation to any other part of the abdomen. He described the pain as constant, burning in nature, and 8 out of 10 in severity. The pain was associated with fever, chills, and nausea. On query, he denied hematuria, urostomy site discharge, flank pain, vomiting, diarrhea, or bloody stools. The patient had been afflicted by multiple UTIs in the last six months, the causal organisms for which included the Morganella species, Vancomycin-resistant enterococci, and Escherichia coli. His symptoms during this 


\section{Cureus}

admission were consistent with those of his previous infections. Surgical history included two herniated cervical disc repairs and suprapubic catheter placement. He was not allergic to any drug in particular. His domiciliary medications included baclofen, gabapentin, docusate sodium, glycerin suppository, mirtazapine, and sertraline. He did not report any significant medical diseases running in his family. He did not report any alcohol, tobacco, or illicit drug use. His ambulation was restricted, necessitating bed confinement and the use of a wheelchair due to paraplegia and spastic deforming contractures. On physical exam, his blood pressure was $124 / 74$, he had a pulse rate of 77 , and his oral body temperature was 98.4 degrees Fahrenheit. His body mass index was $17.63 \mathrm{~kg} / \mathrm{m}$. The remainder of his physical examination was significant for lower extremity contractures. There was no abdominal tenderness and rigidity.

Initial lab work revealed a hemoglobin of $12.4 \mathrm{~g} / \mathrm{dl}$, a white blood count of $11.39 \mathrm{Th} / \mathrm{uL}$, and a platelet count of $286 \mathrm{Th} / \mathrm{uL}$. A basic metabolic panel (BMP) showed a sodium at $143 \mathrm{meq} / \mathrm{L}$, potassium at $4.4 \mathrm{meq} / \mathrm{L}$, chloride at $108 \mathrm{meq} / \mathrm{L}$, bicarbonate at $27 \mathrm{meq} / \mathrm{L}, \mathrm{BUN}$ at $17 \mathrm{mg} / \mathrm{dl}$, and creatinine at $0.7 \mathrm{mg} / \mathrm{dl}$. Blood sugars were at $97 \mathrm{mg} / \mathrm{dl}$. Urinalysis with microscopy revealed purple urine, leukocytes at 21 40/HPF, RBCs at 15 cells/HPF, leukocyte esterase positive, and nitrates positive. Urine was alkalotic with a $\mathrm{pH}$ of 8.5 and a specific gravity of 1.010 . Empirically intravenous ceftriaxone was initiated on a daily basis.

The patient's catheter tubing and bag contained bright purple urine with small amounts of pale colored sediment. Figures 1-2 demonstrate purple-colored urine in the urine bag and catheter tubing, respectively. The patient denied any episodes of purple urine in the past. A urine culture grew Proteus vulgaris resistant to Cefazolin and sensitive to other cephalosporins, trimethoprim/sulfamethoxazole (TMP /SMX), and piperacillin/tazobactam. He was started empirically on ceftriaxone that was continued after culture results, and the following day clear yellow urine had accumulated in his urine bag. The blood cultures remained negative, and his leukocytosis resolved. After being given four doses of intravenous ceftriaxone and a discernible improvement in symptoms, he was discharged from the hospital on a three-day course of TMP /SMX to complete the prescribed seven-day course of antibiotics.

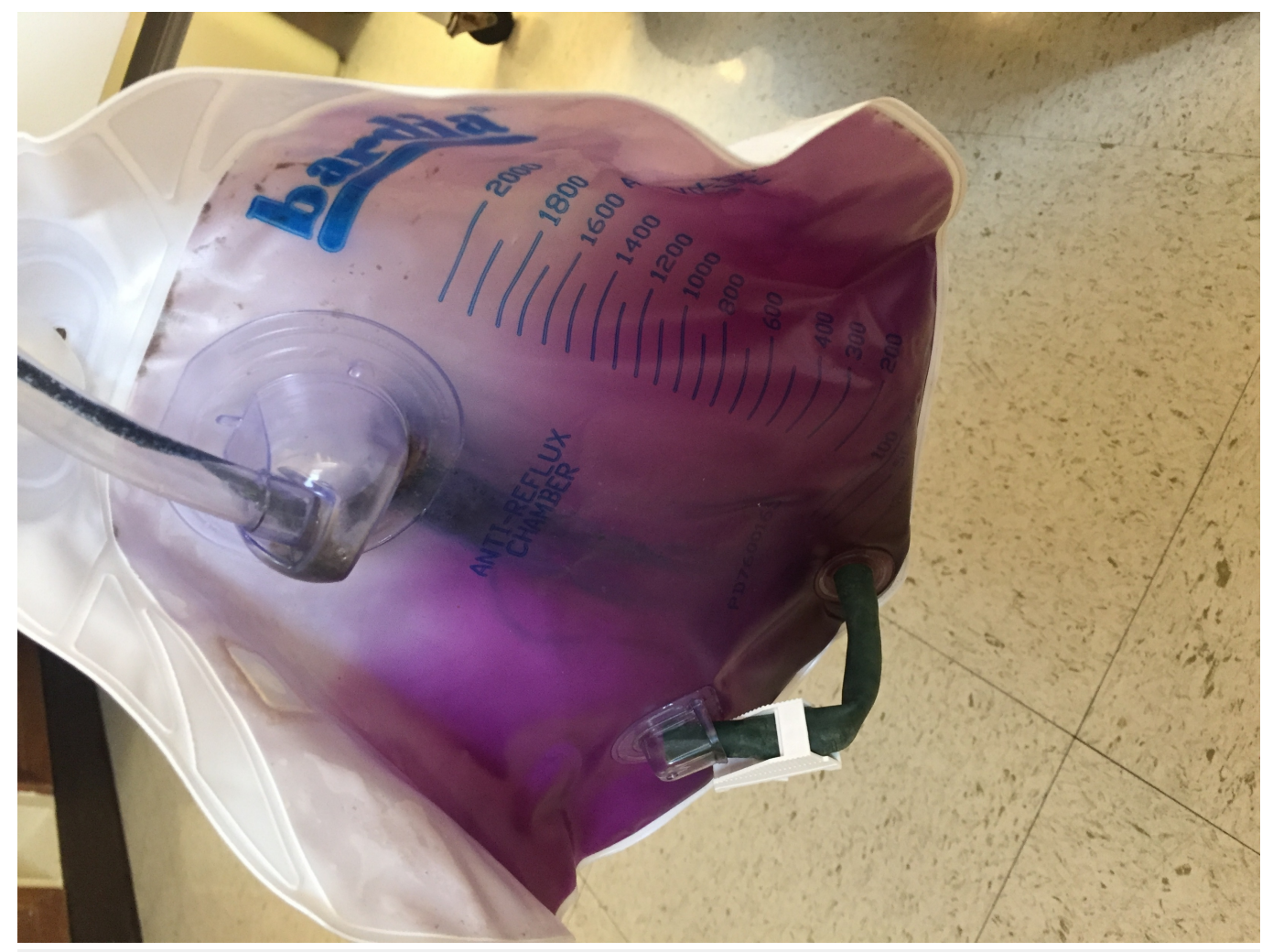




\section{Cureus}

FIGURE 1: Purple urine in urine bag.

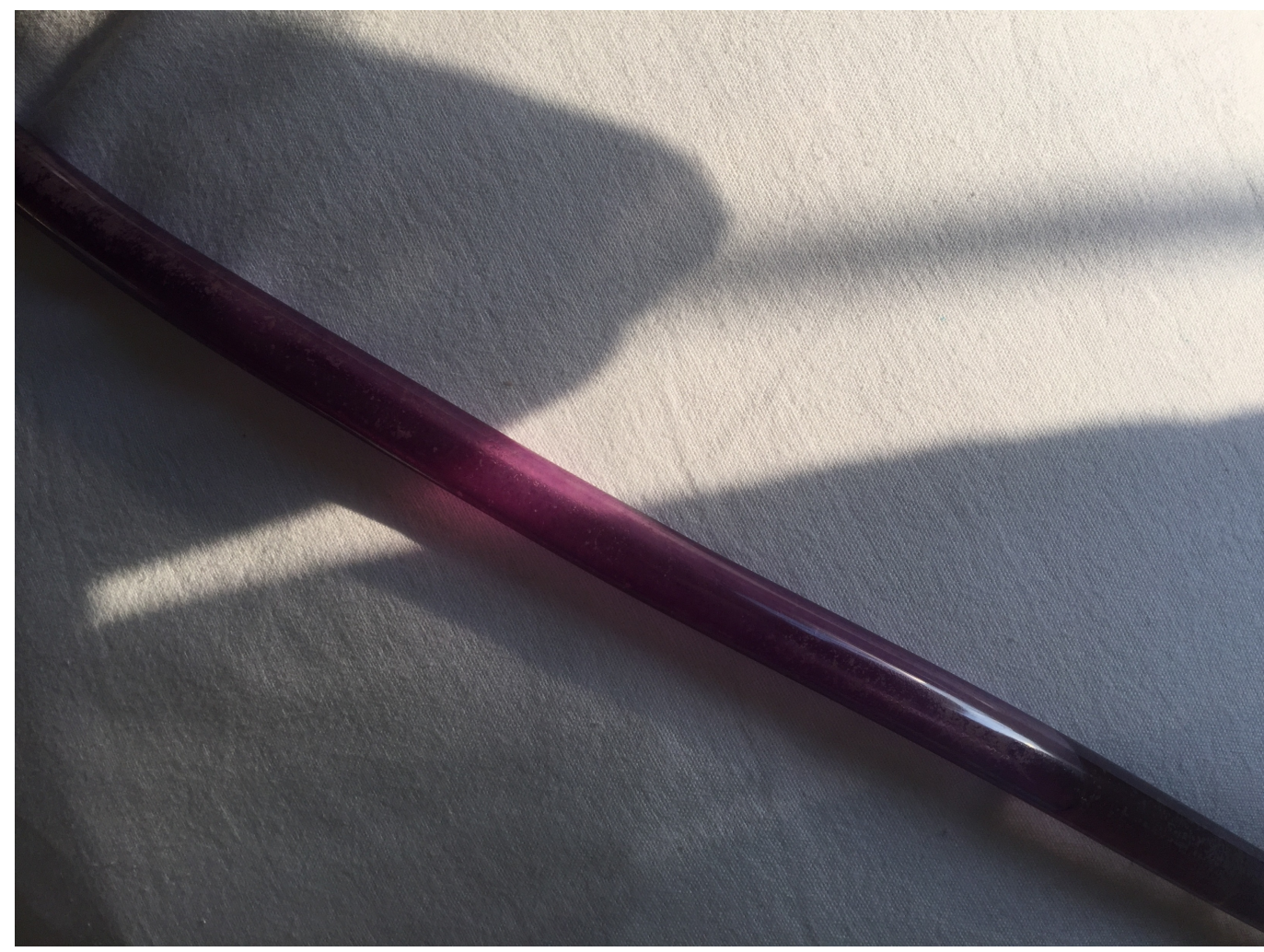

FIGURE 2: Purple urine in catheter tube.

Informed patient consent was obtained for treatment of this patient.

\section{Discussion}

Since its identification in 1978, PUBS has been largely reported in the literature through case reports. A keen study of these reports enlightens us about the most common risk factors which include constipation, chronic catheterization, alkaline urine, polyvinylchloride catheter tubing, and significant disability, all of which were prevalent in our patient. Other factors include female sex, nursing home placement, and laxative suppository [1-2].

Here, we report the first case of PUBS associated exclusively with the pathogen Proteus vulgaris. The most common pathogens encountered in the cultures of urine samples of patients with PUBS are Escherichia coli, Pseudomonas aeruginosa, Klebsiella pneumoniae, Proteus mirabilis, Morganella, Providencia rettgeri, and Providencia stuartii. Only one other report of PUBS associated with Proteus vulgaris was found in the literature, which reported a hemodialysis patient with a urine culture positive for multiple organisms: Escherichia coli, Enterococcus faecalis, and Proteus vulgaris [3]. The pathogenesis of PUBS involves metabolism of dietary tryptophan in the gastrointestinal tract to indole, which, in turn, is conjugated to indole sulfate in the liver. From there, oxidation of the molecule to indigo and indirubin produces both blue and red hues that concentrate in catheters; together, they give a purple appearance [4-5]. The condition is benign and frequently described as rare, despite one reported incidence noted as high as $16 \%$ [2-3]. Resolution is often seen after changing the 
tubing of the catheter system and with antibiotic therapy, as was the case with our patient.

\section{Conclusions}

Purple colored urine is not a clinically irrelevant finding in patients with long-term urinary catheters and should not be overlooked. It may indicate the presence of specific bacteria that have the capacity to change a precursor endogenous substrate to a blue colored metabolite in patients with specific risk factors, such as longstanding physical debility. The list of bacteria that have this capacity is very narrow and includes Escherichia coli, Pseudomonas aeruginosa, Klebsiella pneumoniae, Proteus mirabilis, Proteus vulgaris, Morganella, Providencia stuartii, and Providencia rettgeri.

This information can act as a guide to narrow down the causative organisms and choose appropriate antibiotics for eliminating the same. In addition, normalization of the color of urine can help us to assess the response to therapy, but this finding needs to be validated with additional data, for which ample opportunities are and will be encountered in clinical practice.

\section{Additional Information}

\section{Disclosures}

Human subjects: Consent was obtained by all participants in this study. Conflicts of interest: In compliance with the ICMJE uniform disclosure form, all authors declare the following:

Payment/services info: All authors have declared that no financial support was received from any organization for the submitted work. Financial relationships: All authors have declared that they have no financial relationships at present or within the previous three years with any organizations that might have an interest in the submitted work. Other relationships: All authors have declared that there are no other relationships or activities that could appear to have influenced the submitted work.

\section{References}

1. Mantani N, Ochiai H, Imanishi N, Kogure T, Terasawa K, Tamura J : A case-control study of purple urine bag syndrome in geriatric wards. J Infect Chemother. 2003, 9:53-57. 10.1007/s10156-002-0210-X

2. Su FH, Chung SY, Chen MH, et al: Case analysis of purple urine-bag syndrome at a long-term care service in a community hospital. Chang Gung Med J. 2005, 28:636-642.

3. Wang IK, Ho DR, Chang HY, Lin CL, Chuang FR: Purple urine bag syndrome in a hemodialysis patient. Intern Med. 2005, 44:859-861. 10.2169/internalmedicine.44.859

4. Khan F, Chaudhry MA, Qureshi N, Cowley B: Purple urine bag syndrome: an alarming hue? A brief review of the literature. Int J Nephrol. 2011, 419213: 10.4061/2011/419213

5. Abubacker NR, Jayaraman SM, R K, Sivanesan MK, Mathew R: Purple urine bag syndrome. J Clin Diagn Res. 2015, 9:OD01-OD02. 10.7860/JCDR/2015/14736.6304 